\title{
Correspondence
}

\section{Housing and mental health}

Dear Sirs

I was heartened by the article on training for psychiatrists in housing and community care (Phelan \& Lloyd, Psychiatric Bulletin, August 1993, 17, 487489). If community care is to work well it is vital that all parties should be as well trained and informed as possible.

The Mental Health Foundation is currently very concerned with the mirror image of the needs identified in that article, those of housing providers who need much better understanding of mental health issues.

There is a huge demand, almost completely unmet at present because it has been poorly articulated, for housing staff to have much better information, training and support on mental illness and health services. This need is expressed as much by those managing general housing as it is in the so-called special needs sector of hostels and group homes. The need is reinforced by recent research which shows that as many as $\mathbf{2 4 \%}$ of homeless people with severe mental health problems became homeless when their local authority or housing association tenancy broke down.

In an attempt to address at least some of this need the Mental Health Foundation has joined with two key providers of training for housing staff-Shelter and the National Federation of Housing Associations and with the University of Westminster who run undergraduate and postgraduate housing courses. We have also enlisted the help and advice of Professor Tom Craig, UMDS, St Thomas's.

So far we have run a workshop at a key housing conference and are considering establishing a postgraduate course in housing and mental health. Our main initiative to date, however, has been a one day seminar on mental illness targeted at middle management housing staff. This was so successful and the demand for it so great that we would like to be able to repeat it in various centres around the country and I am hoping that some of your readers might be able to help us with future events.

At the start of the day the majority of attenders were expressing considerable disillusionment with medical services and what was seen as their failure to provide the follow-on support and crisis intervention the housing staff felt was needed. Many felt, therefore, that eviction was often the only option they had to tackle some of the individual situations which they felt had been "dumped" on them. Moreover some said that their organisation ought to refuse to accept any more nominations of people with known mental health problems.

The beginning of the seminar focused on describing, in non medical language, the main symptoms of serious mental illnesses, especially schizophrenia, and the effect those have on people's lives and their ability to cope. For the majority of those present this was the first time they had heard any description of the symptoms or any explanation of the effects, and the revelation that people might, for example, not simply be refusing to pay rent but actually not able to cope with the process of doing so, is clearly going to result in a change in the way that at least some of those present approach rent arrears and a switch away from a punitive, legal approach to something which takes account of the individual's state of health.

Equally useful were sessions which looked at examples of good practice within individual associations (the audience were all from housing associations) but perhaps the highlight of the day was a simple, diagrammatic description of the structure of the health service as it now stands and who is, or at least should be, doing what and how to contact them and what their powers are to act in an emergency.

I do not think I have ever experienced an event at which so much was achieved so quickly with so little. Obviously back in the field many of the difficulties and frustrations will still present themselves but at least 18 housing associations now have one member of staff with greater knowledge and confidence and renewed determination to play their part in community care for the mentally ill. Perhaps the most significant piece of feedback was the comment widely echoed round the room "today has restored my faith in psychiatrists"!

The day I have described was held in London for a selection of associations from around the country. Although the event was not advertised, demand for more has been considerable. The steering group would like to hold a series in regional centres over the next 12 months. We can provide venues and the administration, what we need are some psychiatrists in different parts of the country with an interest in community care who could give a day to come and talk in non medical language about what severe mental illness is, what it does to people's lives, how proper housing support can help and also to be able to help people to understand the structure of the mental health services in their area and how to access them. 
If anyone reading this would like to get involved I would be delighted to hear from them.

JUNE MCKERROW

Director

The Mental Health Foundation

37 Mortimer Street

London WIN $7 R J$

\section{Realising a vision}

\section{DeAr Sirs}

I read with interest Julian Candy's paper 'Realising a Vision: Psychiatry in Aylesbury 1983-91' (Psychiatric Bulletin, August 1993, 17, 458-461) and having worked in Aylesbury throughout those years, both centrally and in the Buckingham Mental Health Service (BMHS) I would like to respond.

One feature of the BMHS is its flexibility and compromise in patient care, qualities not always afforded by many teams. It is interesting to note the title, as the real vision realised throughout those years in Aylesbury Vale was the BMHS - realised on transition from project to service.

Many people recognise and thank Ian Falloon for his progressive ideas on community care and his tenacity in "sticking it out", despite not having the wholehearted support from more traditional colleagues. He has always recognised the significant contribution made by clinicians in allied professions in bringing change and improvements in patient care. He would recognise that innovative services or traditional services do not succeed or fail on the contribution of one individual or profession. Medical commitment to change is not more or less important than any other profession's commitment. Is it not time that psychiatrists developed a sense of proportion about their contribution?

CAROLINE BIRCH
Senior Nurse (Community Mental Health)
Buckingham Mental
Health Service
Buckingham MK18 INV

\section{Reply}

DeAR SIRS

Undoubtedly the BMHS represents the realisation of a vision, and like Caroline Birch I recognise the tenacity and commitment of its founder. My impression is that its capacity for positive flexibility and compromise has grown as it has matured with time (though I cannot speak directly about the last 18 months). However, we in the rest of Aylesbury Vale had a vision too, and not that of one man or one profession; I remember in the early days the chief nurse, the manager and myself thrashing out our 'vision' of a comprehensive service, and discuss- ing then how to share it with and enrich it from the other professions.

Of course, for success commitment from all professions is needed. Writing as I was principally for psychiatrists, I wanted to stress the dangers for them and for the service of remaining aloof from or indifferent to developing CMHTs, something which in other parts the country has had destructive results. Equally, CPNs or social workers or psychologists or OTs who want to remain or become independent practitioners cannot constructively remain in a service which is set on the path of close interprofessional collaboration. I remain convinced though that committed medical input, which indeed the BMHS has enjoyed throughout, is central and essential in any effective service.

\section{Shamrock Way \\ Hythe Marina Village \\ Southampton SO46DY}

\section{Administration of ECT by GP trainees}

\section{DEAR SIRS}

I share Littlejohn's concern (Psychiatric Bulletin, August 1993, 17, 497-498) that GP trainees should not be excluded from ECT rotas. I would argue that it is relevant and useful for such trainees to gain firsthand experience of the technique. ECT continues to cause public concern and, not surprisingly, relatives of depressed patients undergoing ECT frequently visit their own doctor to express worries, and ask about this relative's condition and its treatment. What could be more reassuring than for their own trusted and experienced family doctor to be able to say "when I was training to be a GP, I spent six months in psychiatry during which time I administered ECT myself many times. It is a safe and effective procedure".

Mental illness and its treatment still carry a stigma, and nowhere is this more pronounced than with ECT. Surely we need to ensure that as many nonpsychiatrists as possible gain first-hand experience of the procedure? With correct supervision, the administration of ECT is not so difficult that it cannot be done safely by any doctor. We must avoid adding to the sinister mystique of ECT by hiding it away from branches of our own medical profession. A large number of GP trainees pass through psychiatry and provide a pool of future trained doctors able to give a balanced argument in favour of ECT. This ensures that it is not just psychiatrists who can confirm the benefit of the treatment. ECT can ill afford to lose such valuable advocates.

Friarage Hospital

G. E. P. VINCENTI

Northallerton, North Yorkshire

DL6 IJG 